\title{
Analysis of College Students' Misconception on Geometrical Optics
}

\author{
Setyo Admoko ${ }^{1}$, Titin Sunarti, Mukhayyarotin Niswati Rodliyatul Jauhariyah, Suliyanah, Nadi Suprapto \\ Physics Department \\ Universitas Negeri Surabaya \\ Surabaya, Indonesia \\ ${ }^{1}$ setyoadmoko@unesa.ac.id
}

\begin{abstract}
This research aims to analyze college students' misconception on optical concept. Participants were 36 college students of sixth semester from one intact class. College students' misconception of geometrical optics were measured by a three-tier misconception test. From the data collected we were determined the students' misconceptions profile that find students have misconceptions in each sub-chapter. Then from data analysis we found that: (1) percentage of first tier true answer is higher than percentage of second tier true answer for the whole class, but opposite for all students who suffer misconception (2) there is a significant opposite/negative correlation between students' misconception and the score they get (3) there is no significant correlation between students' score and degree of confidence for their answer to the problem.
\end{abstract}

Keywords-misconception; optical concept; degree of confidence

\section{INTRODUCTION}

Everyone has a perception of his knowledge. He/she processes the information they have in accordance with their individual thinking patterns. Similarly, students experience the process of understanding a concept of physics. Sometimes students can understand correctly according to existing scientific concepts, but sometimes students have a different understanding of the existing scientific concepts and believe that their understanding is true even though it is not in accordance with scientific concepts [1]-[3]. Sometimes students are not stubborn in their belief in the concepts they understand, but they have other concepts that are different from the existing scientific concepts [4]. The difference between the concepts owned by students and the scientific concept is commonly referred to as the term misconception [5$11]$.

Misconceptions can be identified in several ways, including through interviews, open-ended tests, multiplechoice tests, two-tier tests, three-tier tests, or multiple-tier tests [11]. In this study, identification of misconceptions used threetier diagnostic tests adopted from Chen and developed by this researchers team [12]. The three-tier diagnostic test is more effective to distinguish between non-conformist students and students who have the misconception with the added question of belief in choosing the answer, if compared to the two-tier diagnostic test [13-15]. Using three-tier diagnostic tests can be known the profile of students who do not understand the concept, students who have experience misconceptions, and students who understand the concept [16].

Identification of misconceptions needs to be done to find out the right way to implement Physics learning. In optical learning, there are several concepts that allow students to experience misconceptions. However, not all students are aware of that. To change students' understanding of a concept when they experience misconceptions, a way is needed for students to change the concept they have toward the correct scientific concept. In order for the conceptual change to be realized: (1) students need to be aware of the inadequacy of their knowledge, (2) students need to understand the new knowledge given to them, (3) it is necessary for the students to find new information given to them sensitive, (4) students need to use new knowledge given to them to solve new problems they have encountered [17].

Before improving the quality of learning in optical subjects, prior misconceptions were identified through this research. In this study the profile of student answers to the three-tier diagnostic test of optical geometry material was described. Through the student's answer data, the relationship between misconceptions and scores obtained by students was also examined and the relationship between students' beliefs in giving answers to scores obtained.

\section{RESEARCH METHODS}

Given the three-tier diagnostic test instrument to 36 college students on sixth semester from intact clas on physics education program study Universitas Negeri Surabaya (UNESA). The three-tier diagnostic test on geometry optics topis developed by modified from two-tier diagnostic test which developed by Chen et. al. consist of 20 test items [12]. Students gave the combination answer of the concept answer, the reasoning, and beliefs anwer. The students' combination answer categorized into five categories [14] showed by Table I. 
This research focused on students' misconceptions quantitative analysis. To find out the profile of student answers, researchers analyzed the combination of student answers in answering, giving reasons, and giving confidence in the geometrical optics problems presented. Based on a combination of student answers, researchers identified the students misconceptions on the problems presented. Furthermore, an analysis was carried out to determine the relationship between misconceptions and scores obtained by students and an analysis of the relationship between students' level of confidence in the scores obtained by using SPSS.

TABLE I. THE COMBINATION ANSWER OF THREE-TIER TEST [14].

\begin{tabular}{|c|c|c|c|}
\hline Phenomena (P) & Reasoning (R) & Confidence (C) & Category \\
\hline First-tier & Second-tier & Third-tier & Understand the Concept (UC) \\
\hline True & True & Sure & Less Understand the Concept \\
True & True & Unsure & $\begin{array}{c}\text { LUC) } \\
\text { False }\end{array}$ \\
False & Sure & $\begin{array}{c}\text { Do Not Understand the Concept } \\
\text { (NCU) }\end{array}$ \\
\hline True & False & Unsure & Guessing (G) \\
\hline True & False & Sure & Misconceptions (M) \\
\hline False & True & Sure & \\
\hline False & False & Sure & \\
\hline
\end{tabular}

\section{RESUlT DisCUSSION}

The result from 36 college studens response answer to 20 test items can be depicted as Figure 1.

Percentage True Answer, Degree of Confidence and Misconception

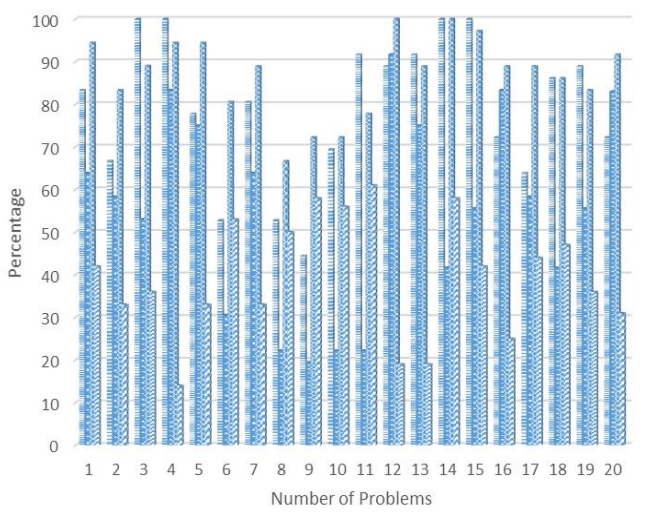

इFirst tier true answer - Second tier true answer * Degree of confidence s Misconception

Fig. 1. The percentage of True Answer, Degree of Confidence and Misconception

Based on Figure 1, in general the answer to the first question (first tiers) or factual question given has the percentage of correct answers higher than the percentage of correct answers to the second question (second tiers) containing the conceptual questions. There are exceptions for numbers 3,12 and 16 .

Meanwhile, the level of confidence in general answers to all questions has a higher percentage than the percentage of correct answers to the second question (second tiers) and also higher when compared to the percentage of correct answers to the first question (first tiers). There are exceptions for numbers $4,11,15$ and 19.
Based on the data above, it can be concluded that conceptual questions have a higher level of difficulty than factual questions.

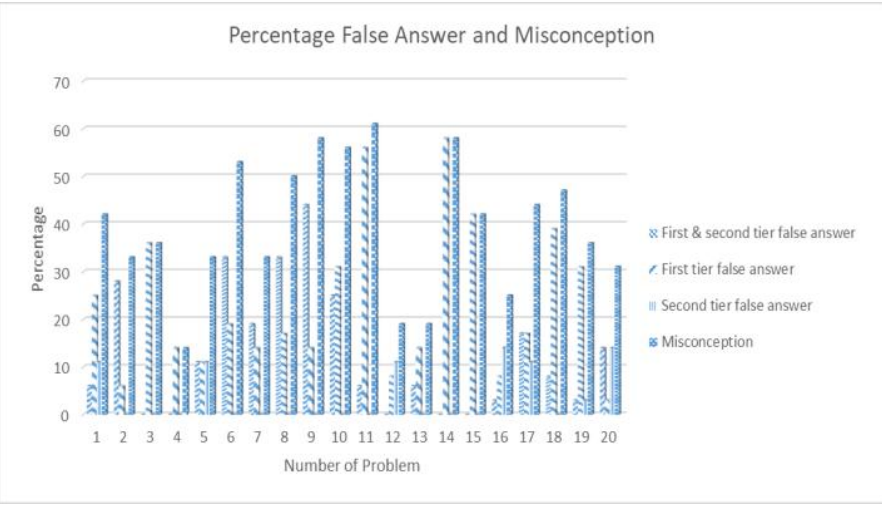

Fig. 2. The percentage of false answer and misconception

Based on the results of the analysis of answers to all answers to misconceptions in all the questions given as shown in Figure 2, the fact that: in general the answers that cause misconceptions occur because students are more wrong in answering the first question (first tier) in this case the question factual. This fact is contrary to the results of the overall class data analysis in Figure 1 which finds the fact that the percentage of correct answers in general is precisely in the first question (first tier) higher than the percentage of correct answers in the second question (second tier) containing conceptual questions. Exceptions only occur in questions number 12 and 16 which get the wrong answer to the second tiers which is the reason for the factual answer.

The items that have high misconceptions (above 50\%) in responses are numbers: $6,9,10,11$, and 14 , where the percentage of misconceptions are 53\%, 58\%, 56\%, 61\% and $58 \%$. Misconceptions about light reflection are represented by numbers: 6, 9, 10 and 1, meanwhile light refraction is represented by number 14 . The misconceptions in this geometrical optics three-tier diagnostic test are explained more clearly in the following Table II.

TABLE II. THE RESULT COLLEGE STUDENTS' MISCONCEPTION ON GEOMETRICAL OPTICS

\begin{tabular}{|c|c|c|c|}
\hline No & Sub Chapter & $\begin{array}{c}\text { Number of } \\
\text { problem }\end{array}$ & Finding Misconception \\
\hline 1 & \multirow{4}{*}{$\begin{array}{l}\text { Light } \\
\text { reflection }\end{array}$} & 6 & $\begin{array}{l}\text { The position of the object's image on } \\
\text { a flat mirror depends on the position } \\
\text { of the observer. }\end{array}$ \\
\hline 2 & & 9 & $\begin{array}{l}\text { The size of the shadow of objects on } \\
\text { a flat mirror will change when the } \\
\text { light source moves from its position. }\end{array}$ \\
\hline 3 & & 10 & $\begin{array}{l}\text { The position of the object's image on } \\
\text { a flat mirror will moves if the } \\
\text { observer moves away from the } \\
\text { mirror. }\end{array}$ \\
\hline 4 & & 11 & $\begin{array}{l}\text { The shadow of a black object on a } \\
\text { flat mirror is produced by a beam of } \\
\text { light from the black object. }\end{array}$ \\
\hline 5 & $\begin{array}{l}\text { Light } \\
\text { refraction }\end{array}$ & 14 & $\begin{array}{l}\text { The source of the refracted light } \\
\text { comes from the eye towards the } \\
\text { object being observed. }\end{array}$ \\
\hline
\end{tabular}


To test whether there is a relationship between several variables, including misconceptions suffered by students, scores obtained and the level of confidence in the answers, an analysis of the answers of each student is done first. The analysis is done by calculating in advance for each student: the score of the correct answer obtained, then determine the level of answer confidence and the number of misconceptions obtained. Where the results of the analysis are presented in Table III.

TABLE III. THE RESULT OF COLLEGE STUDENTS' MISCONCEPTION, SCORE AND CONFIDENCE

\begin{tabular}{|c|c|c|c|c|}
\hline No & $\begin{array}{l}\text { Name Code } \\
\text { of Students }\end{array}$ & Misconception & Score & Confidence \\
\hline 1 & $\mathrm{~A}$ & 8 & 4 & 11 \\
\hline 2 & $\mathrm{~B}$ & 12 & 6 & 19 \\
\hline 3 & $\mathrm{C}$ & 15 & 5 & 20 \\
\hline 4 & $\mathrm{D}$ & 12 & 7 & 20 \\
\hline 5 & $E$ & 12 & 7 & 19 \\
\hline 6 & $\mathrm{~F}$ & 9 & 7 & 17 \\
\hline 7 & $\mathrm{G}$ & 14 & 4 & 17 \\
\hline 8 & $\mathrm{H}$ & 11 & 6 & 17 \\
\hline 9 & I & 8 & 6 & 14 \\
\hline 10 & $\mathrm{~J}$ & 9 & 7 & 15 \\
\hline 11 & $\mathrm{~K}$ & 7 & 8 & 14 \\
\hline 12 & $\mathrm{~L}$ & 12 & 7 & 19 \\
\hline 13 & $\mathrm{M}$ & 6 & 7 & 11 \\
\hline 14 & $\mathrm{~N}$ & 10 & 9 & 20 \\
\hline 15 & $\mathrm{O}$ & 11 & 7 & 19 \\
\hline 16 & $\mathrm{P}$ & 12 & 8 & 20 \\
\hline 17 & Q & 10 & 9 & 19 \\
\hline 18 & $\mathrm{R}$ & 3 & 10 & 13 \\
\hline 19 & $\mathrm{~S}$ & 6 & 10 & 15 \\
\hline 20 & $\mathrm{~T}$ & 7 & 10 & 17 \\
\hline 21 & $\mathrm{U}$ & 10 & 9 & 20 \\
\hline 22 & $\mathrm{~V}$ & 8 & 10 & 18 \\
\hline 23 & $\mathrm{~W}$ & 7 & 12 & 20 \\
\hline 24 & $\mathrm{X}$ & 9 & 10 & 19 \\
\hline 25 & $\mathrm{Y}$ & 10 & 10 & 20 \\
\hline 26 & $\mathrm{Z}$ & 6 & 11 & 17 \\
\hline 27 & AA & 8 & 11 & 20 \\
\hline 28 & $\mathrm{AB}$ & 7 & 13 & 20 \\
\hline 29 & $\mathrm{AC}$ & 3 & 13 & 10 \\
\hline 30 & $\mathrm{AD}$ & 6 & 12 & 17 \\
\hline 31 & $\mathrm{AE}$ & 5 & 15 & 20 \\
\hline 32 & $\mathrm{AF}$ & 6 & 13 & 20 \\
\hline 33 & $\mathrm{AG}$ & 0 & 13 & 13 \\
\hline 34 & $\mathrm{AH}$ & 6 & 14 & 20 \\
\hline 35 & $\mathrm{AI}$ & 5 & 14 & 17 \\
\hline 36 & AJ & 4 & 16 & 19 \\
\hline
\end{tabular}

By using the data listed in Table 3, we examine the relationship between the level of misconception and the score obtained by the college student using SPSS. The results of correlation analysis obtained based on calculations with SPSS can be seen in Table IV.

Based on the results of the correlation test of the relationship between misconceptions with scores obtained by prospective teachers using SPSS as shown in Table 4, it can be stated that the level of student misconception has a significant relationship with students' thinking ability with correlation coefficient -0.740 means that: students' misconception level compare upside down students' thinking skills, (the higher students' thinking skills, the less likely they are to experience misconceptions).

Furthermore, to examine the relationship between the beliefs of prospective teachers in providing answers to scores obtained, it was also done using SPSS, where the results are presented in Table V.

TABLE IV. THE CORRELATION RESULT BETWEEN MISCONCEPTION AND SCORE

\begin{tabular}{|c|c|c|c|}
\hline & & Misconception & Score \\
\hline \multirow[t]{3}{*}{ Misconception } & Pearson Correlation & 1 & $-.751^{* *}$ \\
\hline & Sig. (2-tailed) & & .000 \\
\hline & $\mathrm{N}$ & 36 & 36 \\
\hline \multirow[t]{3}{*}{ Score } & Pearson Correlation & $-.751^{* *}$ & 1 \\
\hline & Sig. (2-tailed) & .000 & \\
\hline & $\mathrm{N}$ & 36 & 36 \\
\hline
\end{tabular}

**. Correlation is significant at the 0.01 level (2-tailed).

TABLE V. THE CORRELATION RESULT BETWEEN SCORE AND CONFIDENCE CORRELATIONS

\begin{tabular}{|l|l|r|r|}
\hline \multicolumn{2}{|c|}{} & Score & Confidence \\
\hline \multirow{4}{*}{ Score } & Pearson Correlation & 1 & .167 \\
\cline { 2 - 4 } & Sig. (2-tailed) & & .331 \\
\cline { 2 - 4 } & $\mathrm{N}$ & 36 & 36 \\
\hline \multirow{3}{*}{ Confidence } & Pearson Correlation & .167 & 1 \\
\cline { 2 - 4 } & Sig. (2-tailed) & .331 & \\
\cline { 2 - 4 } & $\mathrm{N}$ & 36 & 36 \\
\hline
\end{tabular}

Furthermore, the correlation test results of the relationship between the acquisitions of scores with a level of confidence in the answers of prospective teachers using SPSS as shown in Table 5. Based on the value of the correlation coefficient is very small that is 0.167 and is in the rejection area it can be stated that the acquisition of college student do not have a significant relationship with level of confidence in the answer.

\section{CONCLUSION}

The collage student's misconception profile shows that collage students are experiencing misconceptions throughout the sub-chapter of image formation on a flat mirror (light reflection) and light refraction by two different medium. The highest misconception lies in the sub-chapter of formation of black body shadows on a flat mirror with a percentage of $61 \%$.

From result discussion we conclude that: (1) percentage of first tier true answer is higher than percentage of second tier true answer for the whole class, but opposite for all students who suffer misconception (2) there is significant opposite/negative correlation between students' misconception and the score they get (3) there is no significant correlation between students' score and degree of confidence for their answer to the problem.

Based on the findings of this study, the researcher suggested to the teacher that in his lectures to ensure that factual knowledge had been fully understood by students before teaching conceptual knowledge, and the teacher in assessing the understanding of concepts obtained by students 
did not just believe in students' recognition but had to do it by testing understanding of concepts comprehensively.

\section{REFERENCES}

[1] O. Ozcan and C. Gercek, "Students' Mental Models of Light to Explain the Compton Effect," Procedia - Soc. Behav. Sci., vol. 191, pp. 2195 2197, 2015

[2] H. B. Aşcı, F. Z. Tan, and F. Altıntaş, "A Strategic Approach for Learning Organizations: Mental Models," Procedia - Soc. Behav. Sci., vol. 235, pp. 2-11, 2016.

[3] J. Goodhew, S. Pahl, S. Goodhew, and C. Boomsma, "Mental models: Exploring how people think about heat flows in the home," Energy Res. Soc. Sci., vol. 31, pp. 145-157, Sep. 2017.

[4] C. J. Wenning, "Dealing more effectively with Alternative Conception in Science" J. Physc. Teach. Educ., vol. 5, pp. 11, 2008.

[5] F. Türker, "Developing a Three-Tier Test to Assess High School Students' Misconceptions Concerning Force and Motion" Cankaya/Ankara: Thesis of Middle East Technical University, December 2005.

[6] H. Peşman, Development of a Three-Tier Test to Assess Ninth Grade Students' Misconceptions About Simple Electric Circuits. Cankaya:Ankara: Thesis of Middle East Technical University, 2005.

[7] D. K. Gurel, A. Eryllmaz, and L. C. McDermott, "A Review and Comparison of Diagnostic Instruments to Identify Students' Misconceptions in Science", Eurasia J. Math., Sci., \& Tech. Edu., vol. 11, pp. 989, 2015.

[8] D. K. Gurel, A. Eryilmaz, and L. C. McDermott, "Identifying preservice physics teachers' misconceptions and conceptual difficulties about geometrical optics,” Eur. J. of Phys., vol. 37, pp. 045705, 2016.
[9] S. W. Chan and Z. Ismail, "Assesing Misconceptions in Reasoning about Variability among High School Students," Procedia - Soc. Behav. Sci., vol. 93, pp 1478-1483, 2013.

[10] B. Djanette and C. Fouad, "Determination of university students' misconceptions about light using concept maps", Procedia - Soc. Behav. Sci., vol. 152, pp. 582-589, 2014.

[11] X. Vamvakoussi and S. Vosniadou, " How A Review and Comparison of Diagnostic Instruments to Identify Students' Misconceptions in Science Many Decimals Are There Between Two Fractions? Aspects of Secondary School Students' Understanding of Rational Numbers and Their Notation,", Cog. \& Instruct., vol. 28, pp 181, 2010.

[12] Chung-Chih Chen, Huann-Shyang Lin, Ming-Liang Lin, "Developing a Two-Tier Diagnostic Instrument to Assess High School Students' Understanding - The Formation of Images by a Plane Mirror," Proc. Natl. Sci. Counc. ROC(D) Vol. 12, No. 3. pp. 106-121, 2002.

[13] Z. D. Kirbulut, and O Geban, "Using three-tier diagnostic test to assess students' misconceptions of State Matter", Eur. J. Math. Sci. Tech. Educ., vol. 10, issue 5, pp. 509-521, 2014.

[14] M. N. R. Jauhariyah, I Zulfa, Z. Harizah, and W. Setyarsih, "Validity of Student's Misconceptions Diagnosis on Chapter Kinetic Theory of Gases Using Three-Tier Diagnostic Test,” J. Phys: Conf. Ser., vol. 1006, $012005,2018$.

[15] Suliyanah, H. N. A. Putri, and L. Rohmawati, "Identification of Heat and Temperature Using Three-Tier Diagnostic Test," J. Phys. Conf:. Ser., vol. 997, 012035, 2018.

[16] M N R Jauhariyah , N. Suprapto, Suliyanah, S. Admoko, W. Setyarsih, Z. Harizah, and I. Zulfa, "The Students' misconceptions profile on chapter gas kinetic theory," J. Phys.: Conf. Ser. 997 012031, 2018.

[17] Süleyman Aydın, "Eliminating the misconceptions about image formation in plane mirrors by conceptual change texts," International J Soc. Sci. Edu. Res. Volume: 3(4), 2017. 


\section{Appendix}

The sample five biggest misconception of test item of Geometrical Optics three-tier diagnostic test instrument:

(Chen et al., 2002)

6. As shown in the left figure, a plane mirror and a pencil are placed on top of a table. A boy and a girl sit side by side in front of the table, looking into the mirror. The relative locations of the pencil, mirror, boy and girl are shown on the right.

(1) Which of the following statements is correct? (Please check)

(A) The locations of the image seen by both students are the same.

(B) The location of the image seen by the boy is on the right side of that seen by the girl.

_(C) The location of the image seen by the boy is on the left side of that seen by the girl. _(D)

(2) Which of the following ray diagrams can best explain your answer?
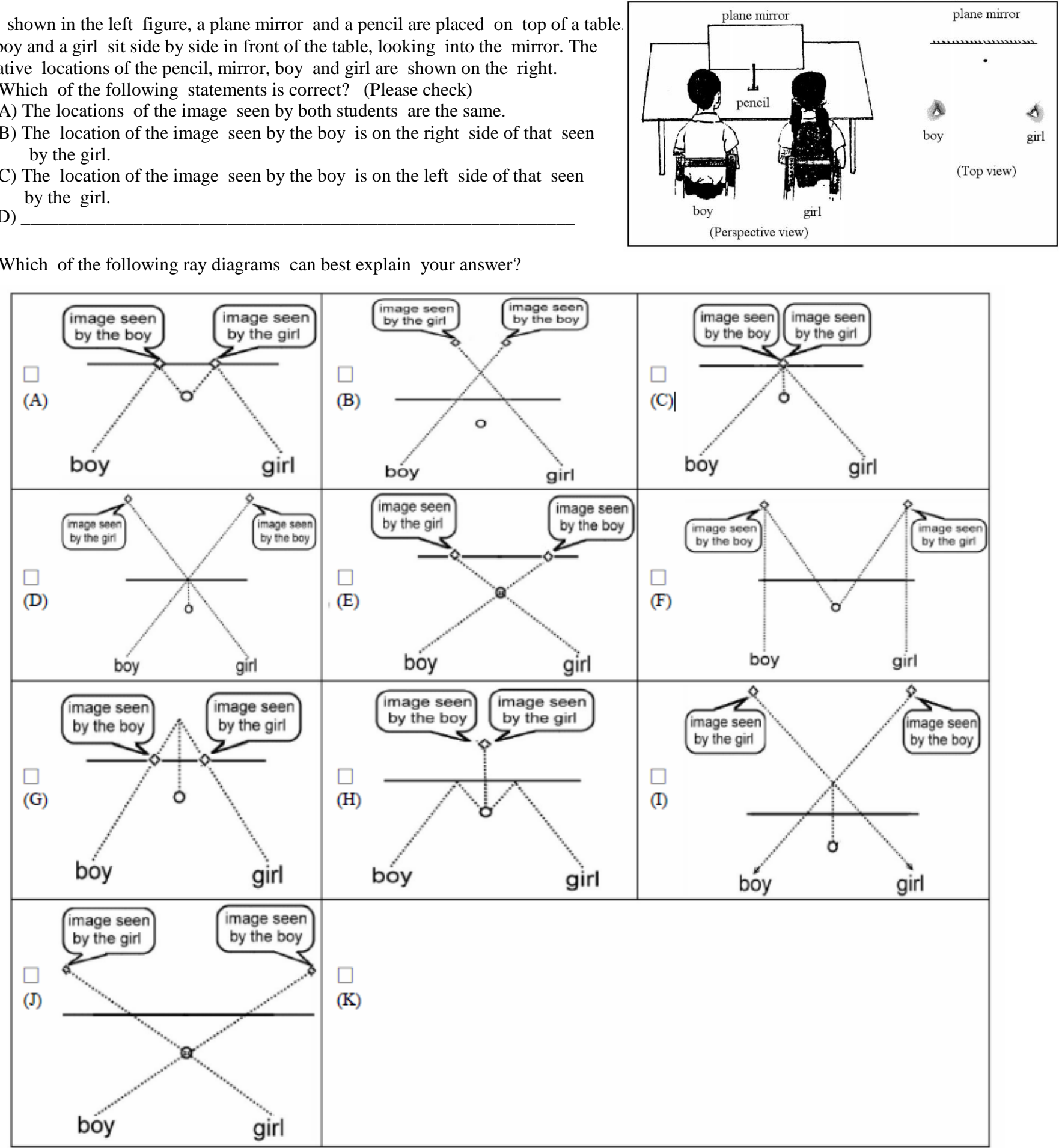

(3) Are you sure about your answer?
(A) Sure
(B) Not sure 
9. A plane mirror and a pencil are placed on a tabletop. An observer is looking into the mirror to observe the image of the pencil. The experiment is performed in a darkened room. A lamp is the only illuminant inside the room.

If the lamp is raised a little higher, what will happen to the image of the pencil seen by the observer? (1) Please check:

_(A) The image will become longer.

_(B) The image will become shorter.

_(C) The image will remain unchanged.

-(D)

(2) Which of the following ray diagrams can best explain your answer? (The dotted and solid lines indicate the light ray paths, before and afte the lamp is raised.)

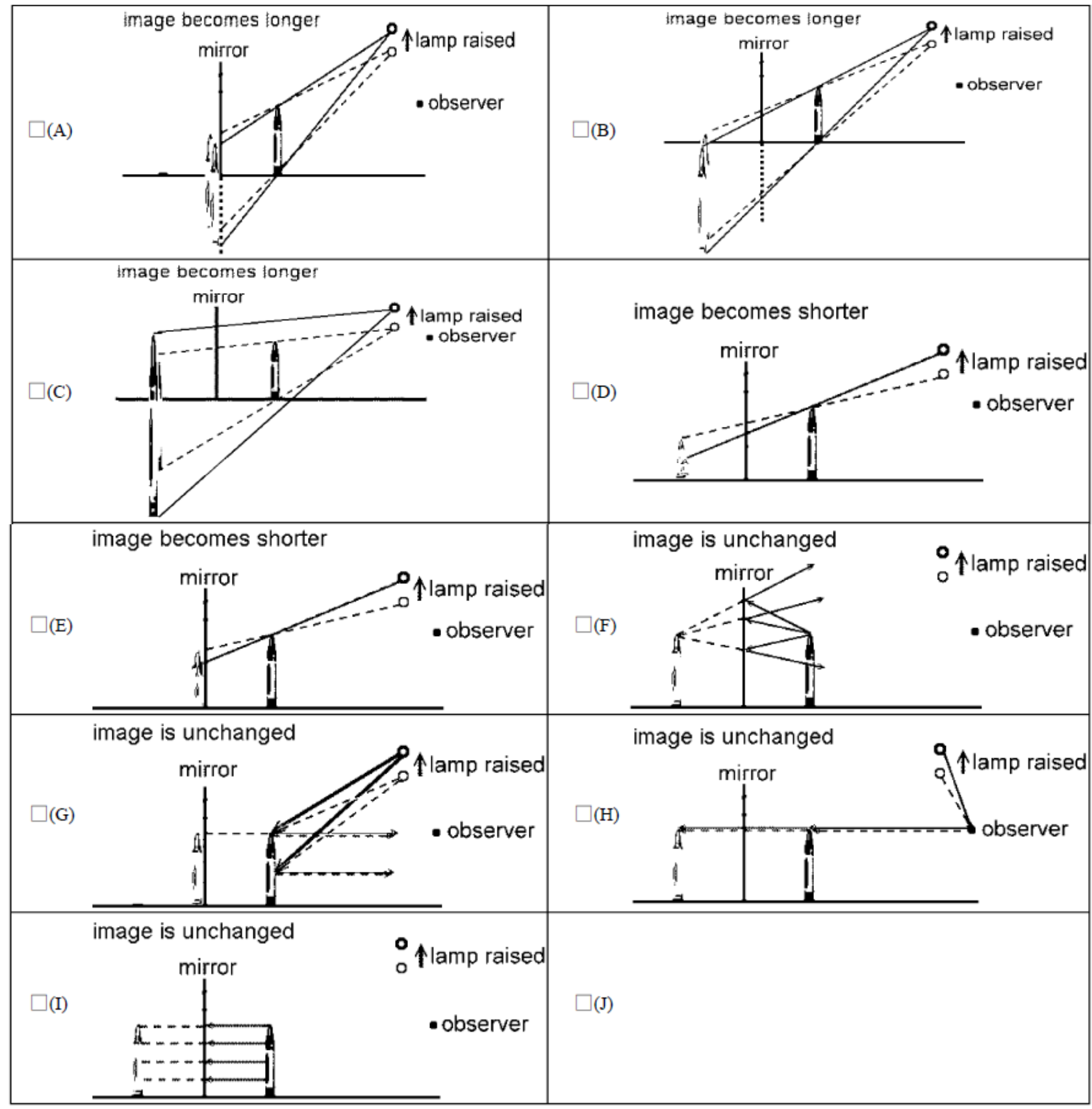

(3) Are you sure about your answer?
(A) Sure
(B) Not sure 
10. A plane mirror and a pencil are placed on a tabletop. An observer is looking into the mirror to observe the image of the pencil. The experiment is performed in a darkened room. A lamp is the only illuminant inside the room. If the observer moves a little farther from the mirror while the lamp stays fixed, what will happen to the location of the image of the pencil seen by the observer?

(1) Please check:
(A) It will retreat from the mirror
_(B) It will approach the mirror.
_(C) It will stay at the same location.
(D)

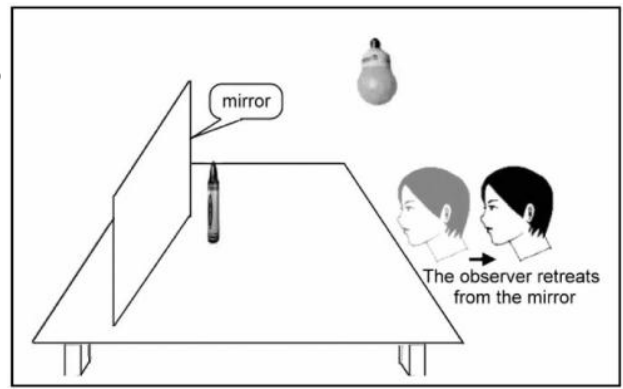

(2) Which of the following ray diagrams can best explain your answer? (The dotted and solid lines indicate the light ray paths, before and after the observer retreats from the mirror.)

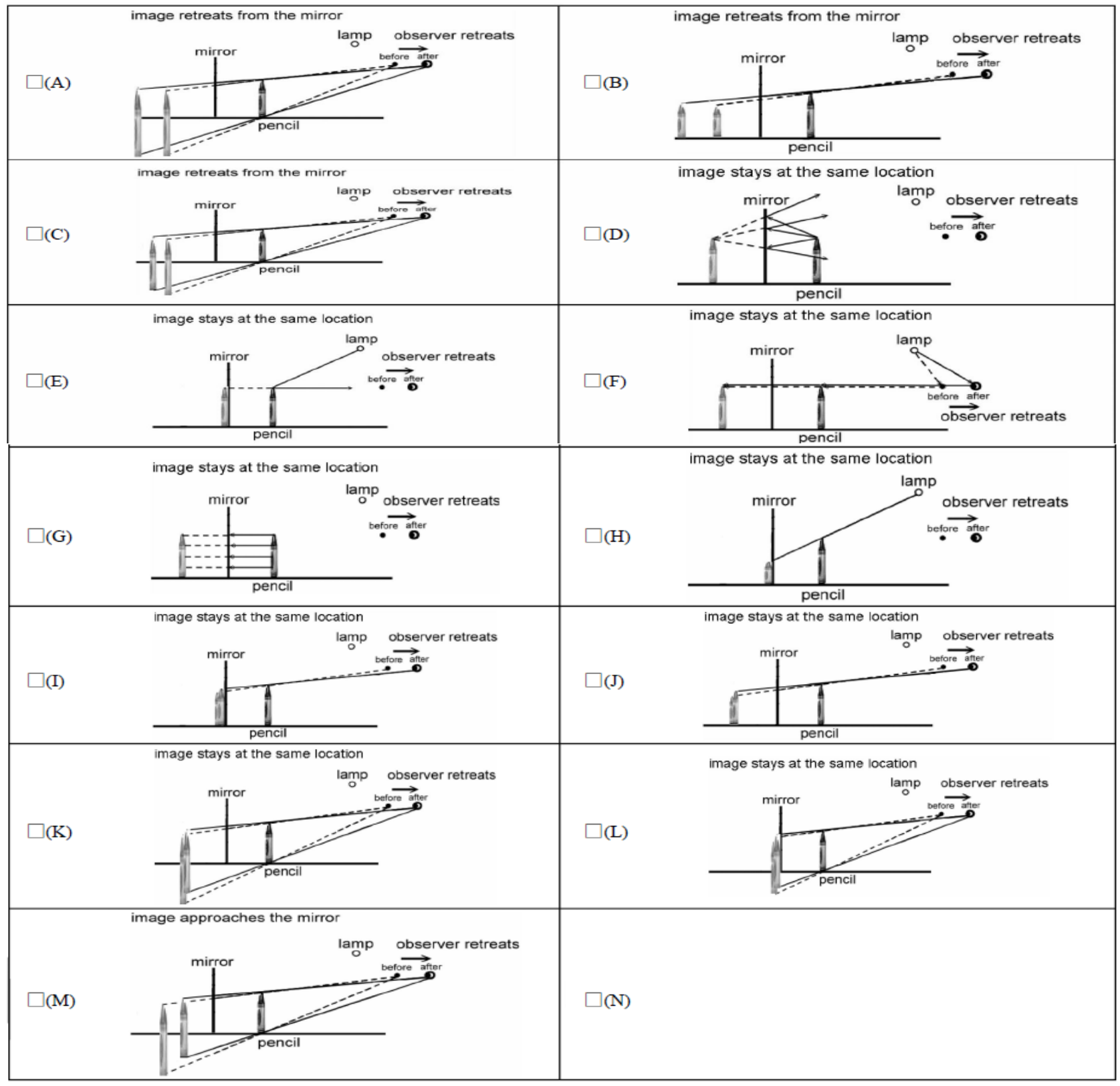

(3) Are you sure about your answer?
(A) Sure
(B) Not sure 
11. As shown in the figure, a white ball is placed in front of a plane mirror. An observer can see the white ball in the mirror. Then, the white ball is replaced with a black one.

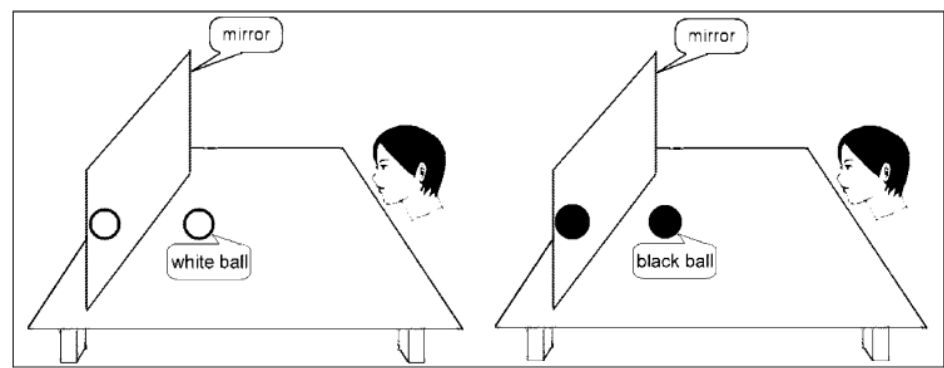

(1) Which of the following statements is correct?
(A) The observer can see the black ball in the mirror.
_(B) The observer can't see the black ball in the mirror.
(C)

(2) Which of the following statements can best explain your answer?

_(A) The black ball scatters external light, some of which heads toward and reflects from the mirror.

_(B) The black ball emits light, some of which heads toward and reflects from the mirror.

_(C) The black ball neither scatters nor emits light.

(D) The lines of vision from the observer reflect from the mirror and then impinge on the black ball. (E)

(3) Are you sure about your answer?
(A) Sure
(B) Not sure

14. When we see coin in the bottom of the swimming pool filled with water.

(1) The coin will appear...

(A) Deeper than its real position

(B) Shallower than its real position

(C) Equal to its real position

(D) No conclusion

(E)

(2) Which diagram of the process of shading the shadows forming below fits and explains your answer? (dotted lines and solid lines indicate the extension of the beam and the actual line of light)

\begin{tabular}{|l|l|}
\hline & \\
\hline & \\
\hline
\end{tabular}

(3) Are you sure about your answer?
(A) Sure
(B) Not sure 